\title{
Influência de épocas de corte no acúmulo de fitomassa de forrageiras sob irrigação e sequeiro
}

A irrigação de pastagem tropical é tida como uma alternativa econômica para a produção de leite e carne, tornando-se uma técnica desejável por apresentar vantagens como a minimização da sazonalidade durante o ano, sendo o intervalo de cortes determinante para a produção e a qualidade de forrageiras. O objetivo deste trabalho foi verificar a produção de fitomassa de espécies forrageiras, quando cultivadas em condições de sequeiro e irrigadas em três épocas de cortes. O experimento foi conduzido em uma propriedade, localizada nas coordenadas geográficas $15^{\circ} 36^{\prime} 55^{\prime \prime}$ de Latitude Sul e $58^{\circ} 46^{\prime} 43^{\prime \prime}$ de Longitude Oeste com atitude de $207 \mathrm{~m}$. O delineamento experimental utilizado foi o de blocos casualizados em esquema fatorial $5 \times 3$, sendo forrageiras: brizantha marandu (Brachiaria brizantha cv. marandu), capim mombaça (Panicum maximum cv. mombaça) cultivados sob condições de irrigação e sequeiro e tifton 85 (cynodon sp.) irrigado e as épocas de corte 25 , 50 e 75 dias, com 5 repetições. A área experimental, de 5,5 ha-1, foi dividida em 25 piquetes de 0,22 ha-1, igualmente distribuídos entre os 5 tratamentos. A produção do Capim Mombaça (Panicum maximum cv. mombaça) quando cultivado com irrigação apresentou maior altura e produção fitomassa quando comparado com as demais forrageiras avaliadas. Após as investigações ficou evidente que a altura do relvado e produção de fitomassa não foram influenciadas pela época de corte.

Palavras-chave: Altura do Relvado; Massa Fresca; Massa Seca.

\section{Influence of cutting times in the phytomass accumulation of foragees under irrigation and drought}

\footnotetext{
The irrigation of tropical pasture is considered an economic alternative for the milk and meat production. It is a desirable technique because it presents advantages such as the minimization of seasonality during the year, the cut interval being decisive for the production and quality of forage. The objective of this study was to verify the production of phytomass production of forage species, when planted under drought and irrigation conditions, during three cut times. The experiment was conducted on a property located at geographical coordinates $S$ $15036^{\prime} 55^{\prime \prime}$ and WGr 58046 '43" at an altitude of $207 \mathrm{~m}$. The experimental design was a randomized complete block design in a $5 \times 3$ factorial scheme with the following forages: Brizantha marandu (Brachiaria brizantha cv. Marandu), Mombaça grass (Panicum maximum cv. Mombaça) cultivated under irrigation and drought conditions and tifton 85 (cynodon sp.), irrigated and cutting times 25,50 and 75 days, with 5 replications. The experimental area of 5.5 ha-1, was divided into 25 paddocks of 0.22 ha-1,equally distributed among the 5 treatments. The production of Capim Mombaça (Panicum maximum cv. Mombaça) when cultivated with irrigation showed higher height and phytomass production when compared to the other forages evaluated. After the investigations it was evident that the height of the lawn and phytomass production was not influenced by the cutting season.
}

Keywords: Lawn Height; Fresh Weight; Dry Weight.

Topic: Química Agrícola e Ambiental

Reviewed anonymously in the process of blind peer.

Esvanio Edipo da Silva Ferreira

Universidade Federal de Mato Grosso, Brasil

http://lattes.cnpq.br/8821951727659938

esvanioedipo@hotmail.com

\section{Keller Regina Soares}

Universidade Federal de Mato Grosso, Brasil

http://lattes.cnpq.br/4202337628291300

kelleragronomia@hotmail.com

\section{Eurípedes Maximiano Arantes}

Universidade do Estado de Mato Grosso, Brasil

http://lattes.cnpq.br/2621730639049453

emarantes@brturbo.com.br

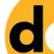

DOI: 10.6008/SPC2179-6858.2017.001.0010
Received: 18/04/2016

Approved: 20/05/2016

\author{
Rodolpho Alexandre Casadei \\ Universidade Federal de Lavras, Brasil \\ http://lattes.cnpq.br/6869145901480081 \\ dani rodolpho@hotmail.com \\ Daniela Soares Alves Caldeira \\ Universidade do Estado de Mato Grosso, Brasi \\ http://lattes.cnpq.br/5022149451105869 \\ danielacaldeira@unemat.br
}

Referencing this:

FERREIRA, E. E. S.; SOARES, K. R.; ARANTES, E. M.; CASADEI, R. A.; CALDEIRA, D. S. A.. Elnfluência de épocas de corte no acúmulo de fitomassa de forrageiras sob irrigação e sequeiro. Revista lberoAmericana de Ciências Ambientais, v.8, n.1, p.119-128, 2017. DOI: http://doi.org/10.6008/SPC2179-6858.2017.001.0010 


\section{INTRODUÇÃO}

A pecuária representa uma das mais importantes atividades para a agricultura familiar no Brasil, sendo que a principal atividade desenvolvida é a produção de leite a pasto. Em função de sua menor vulnerabilidade à seca quando comparada às explorações agrícolas, a pecuária leiteira tem se constituído num fator importante para a manutenção do homem no campo através da geração de emprego e renda. No entanto, a redução de oferta de alimentos no período da seca aliada com a limitada área dos estabelecimentos rurais, tem ocasionando baixo desempenho produtivo dos rebanhos (LIMA et al., 2004).

Grande parte dos rebanhos leiteiros alimentam-se basicamente de pastagens, tanto nativa como cultivadas, por ser esta a principal e mais barata fonte de alimento para esses animais, que transformam eficientemente a fibra em energia para sua manutenção e produção (AZEVEDO JÚNIOR, 2011).

Nesse sentido, fica claro a importância da pastagem para a produção animal e por isso deve ser entendida como um dos principais fatores produtivos. Entretanto de acordo com Ferreira e Zanine (2007), o sistema de produção animal é muito mais complexo e dinâmico do que se possa parecer, sendo composto por diversos fatores que interagem entre si, tais como solo, planta, clima, animais e ação antrópica.

Dentre os fatores que exercem influência na produção de forrageiras, Alves et al. (2000) aponta que a interação edafoclimática, exerce efeito decisivo na produção forrageira, determinando o potencial e a sustentabilidade da produção do pasto. Entre os componentes do solo, destaca-se a baixa fertilidade natural da maioria dos solos brasileiros, que tem limitado a capacidade produtiva da pastagem (SCALEA, 1997). Além disso, irregularidade de distribuição ou insuficiência de chuva ao longo do ano, associada a outros componentes climáticos, determinam um padrão estacional de produção de forragem, ou seja, 75\% ou mais da produção de forragem concentra-se nos meses quentes e chuvosos, enquanto que no período seco a produção em quantidade e qualidade de pasto ocorre de forma deficitária (ROLIM, 1980).

De acordo com Drumond (2003), a água é um dos principais fatores que restringem o desenvolvimento das culturas e a irregularidade do regime pluviométrico em algumas regiões pode tornarse uma restrição ao desenvolvimento agrícola. Para obtenção de alta produtividade das forragens, podem ser utilizadas técnicas de irrigação, permitindo que a distribuição de água de maneira artificial em pastagens se torne garantia de produção como o planejado (CUNHA et al., 2007). Assim, a irrigação de pastagem tropical tem sido apontada como uma das estratégias reguladoras da produção e como técnica de manejo para reduzir o efeito da estacionalidade de produção das pastagens. Respostas produtivas das pastagens por meio da irrigação parecem estar mais ligadas as condições climáticas, tanto na ocasião quanto na frequência de irrigação, que as características fisiológicas das espécies de gramíneas.

O uso da irrigação em pastagens permite um aumento da capacidade de produção da propriedade, sem a necessidade de aumento da área; possibilita a minimização da sazonalidade durante o ano; substitui outras práticas de produção, durante o inverno, com menor custo; acelera o ciclo de produção como um todo; ganho de mercado através da venda de animais precoces para o abate; entre outras (YASSU et al., 1998). Teodoro (2002) enfatiza que a irrigação de pastagem tem como objetivo equilibrar a produção da 
pastagem entre as estações de verão e inverno, eliminando a necessidade de suplementação volumosa no período da seca, intensificando assim a produção animal por área, obtendo-se maiores lucros no desenvolvimento da atividade.

Segundo Drumond e Aguiar (2005), a irrigação pode ser uma alternativa para a produção intensiva de carne e leite em pequenas áreas, se a temperatura não for um fator limitante, sendo possível manter produção satisfatória durante o período da seca.

Outra técnica de manejo que contribui para determinar a produção e a qualidade de forrageiras (GONÇALVES et al., 2002) é o intervalo de cortes a que se submete essas plantas. Cortes a intervalos menores resultam em baixas produções de matéria seca. Não obstante, a alta relação folha/colmo determina valor nutritivo mais elevado (RADIS, 2010).

Dessa maneira, o objetivo deste trabalho foi verificar a produção de fitomassa de espécies forrageiras cultivadas em condições de sequeiro e irrigadas em três épocas de cortes, na região Sudoeste do Estado de Mato Grosso.

\section{METODOLOGIA}

O presente trabalho foi executado em uma área que faz parte do projeto "Unidade Didática de Sustentação Econômica - Irrigação de Pastagens", conduzido pela EMPAER (Empresa Mato-Grossense de Pesquisa, Assistência e Extensão Rural S/A), no município de Figueirópolis D’Oeste - MT, com coordenadas geográficas $15^{\circ} 36^{\prime} 55^{\prime \prime}$ de Latitude Sul e $58^{\circ} 46^{\prime} 43^{\prime \prime}$ de Longitude Oeste com atitude de $207 \mathrm{~m}$. O solo da área é o ARGISSOLO VERMELHO ESCURO Eutrófico (EMBRAPA, 2013), com relevo ondulado e o clima local, segundo a classificação de Köppen é, predominantemente, o tropical quente e úmido AWa, com inverno seco. O período das águas vai de novembro a março, com maior índice pluviométrico nos meses de dezembro e janeiro, e o período da seca, vai de abril a outubro. A precipitação pluviométrica, a temperatura e a umidade relativa apresentam médias anuais de $1.224 \mathrm{~mm}, 25$, 33 C e 80\%, respectivamente (SEPLAN, 2007).

A área experimental foi constituída por $5,5 \mathrm{ha}^{-1}$, cultivados com forrageiras sendo $3,3 \mathrm{ha}^{-1}$ irrigados e 2,2 ha ${ }^{-1}$ em condições de sequeiro. A área experimental foi dividida em 25 piquetes de 0,22 ha $^{-1}$, igualmente distribuídos entre os 5 tratamentos. Os piquetes foram dispostos lado a lado, separado por cerca elétrica.

O delineamento experimental utilizado foi o de blocos casualizados, com 5 repetições, em esquema fatorial $5 \times 3$. Os fatores avaliados foram: brachiaria (Brachiaria brizantha cv. Marandu) irrigada e em sequeiro; capim mombaça (Panicum maximum cv. Mombaça) com irrigação e sem irrigação e tifton 85 (Cynodon sp.) irrigado. Não foi avaliado tifton 85 (Cynodon sp.) em sequeiro, pois na propriedade só existe esta forragem sob irrigação. Dessa forma, optou-se em mantê-lo no estudo para fins de comparação com as demais forragens estudadas. $O$ segundo fator avaliado foi a influência de três épocas de corte (aos 25, 50 e 75 dias) na produção de fitomassa dessas forragens.

O preparo do solo foi realizado foi realizado com uma aração seguida de uma gradagem e destorroamento com enxada rotativa, com finalidade de revolver o solo, descompactar camadas superficiais e destruir o material vegetal presente na área. 
A semeadura foi realizada com auxílio do distribuidor de adubos e sementes a lanço, marca Marchesan, modelo DCA 1200, seguida de incorporação de sementes a uma profundidade de $2 \mathrm{~cm}$, com uma grade niveladora fechada.

As forrageiras foram irrigadas diariamente, das 21:00 às 6:00 horas da manhã, perfazendo um total de 9 horas. Para cada piquete irrigado, utilizou-se 12 aspersores distribuídos em linha, sendo o sistema de irrigação adotado o do tipo aspersão rotativo com pressão de serviço de 20 m.c.a. A determinação do número de horas a qual foi fornecido água as forragens, ocorreu em função da vazão do conjunto motobomba e dos aspersores utilizados.

A produção de fitomassa da parte aérea foi obtida em três épocas de corte (25, 50 e 75 dias) para as forrageiras de interesse, onde foi avaliado a altura do relvado, massa fresca e massa seca, adotadas de acordo com a necessidade de rotação do gado e foi mensurada entre os meses de agosto e outubro.

A coleta de dados foi realizada de acordo com a metodologia proposta por Pedreira (2002), com o lançamento da moldura de 1,0 $\mathrm{m}$ ao acaso em cinco pontos de cada piquete antes de cada pastejo. Após o lançamento foi realizada a medição da ARPRP - altura do relvado no pré-pastejo com uma régua graduada em centímetros dentro da moldura por piquete avaliado. A altura média por piquete correspondeu a altura média do horizonte de folhas em torno da régua. A metodologia propõe ainda o corte da matéria fresca dentro da moldura á $15 \mathrm{~cm}$ com o auxílio de uma tesoura; limpeza do material morto e demais impurezas e, pesagem da massa fresca cortada em balança digital com a precisão.

As amostras de massa fresca coletadas foram conduzidas ao laboratório de botânica da Universidade do Estado de Mato Grosso, campus de Cáceres. Para evitar a desidratação da massa colhida, esta foi acondicionada em caixa isotérmica com gelo e encaminhada ao laboratório. As amostras foram pesadas e colocadas em estufa de ventilação forçada a $65^{\circ} \mathrm{C}$ por 72 horas, para determinação da massa seca.

Os dados obtidos foram submetidos a análise de variância e as médias comparadas pelo teste Tukey a 5\% de probabilidade, utilizando o software Assistat - Assistência Estatística (v. 7.6 beta).

\section{RESULTADOS E DISCUSSÃO}

Encontra-se na Tabela 1, o resumo da análise de variância, onde se observa diferenças significativas entre as espécies de forrageiras para todas as variáveis avaliadas. Verifica-se, ainda que não ocorreu influência da época de corte em nenhuma variável avaliada, mas houve efeito da interação entre espécies e época de corte, tanto na produção de massa fresca como na seca.

Estes resultados diferem dos obtidos por Detomini (2004), em trabalho sobre modelagem da produtividade potencial de brachiaria brizantha (variedades cultivadas Marandu e Xaraés). 0 autor não encontrou diferença significativa na produção de fitomassa fresca e seca para estas variedades.

Restle et al. (2000), também não observaram efeito significativo nem da interação da época de corte $\mathrm{x}$ espécie, nem dos fatores avaliados. 
Os valores dos coeficientes de variação indicaram uma boa precisão experimental. Azevedo Júnior (2011), obteve valores de coeficiente de variação de 7,4 \% para altura do dossel e 20,5\% para massa seca total.

Tabela 1: Resumo da análise de variância (quadrado médio) para Altura de Relvado (cm) e produção de Fitomassa (t/ha) por espécies forrageiras cultivadas sob irrigação e sequeiro.

\begin{tabular}{|c|c|c|c|c|}
\hline $\begin{array}{l}\text { Fonte de } \\
\text { Variação }\end{array}$ & $\mathrm{G} / \mathrm{L}$ & $\begin{array}{l}\text { Altura do } \\
\text { Relvado }\end{array}$ & $\begin{array}{l}\text { Massa } \\
\text { Fresca }\end{array}$ & $\begin{array}{l}\text { Massa } \\
\text { Seca }\end{array}$ \\
\hline Espécies (a) & 4 & $16800,5522^{* *}$ & $613,4875^{* *}$ & $94,7467^{* *}$ \\
\hline Época de Corte (b) & 2 & $6,2146^{\mathrm{ns}}$ & $0,6091^{\mathrm{ns}}$ & $0,01533^{\mathrm{ns}}$ \\
\hline Interação ( $a$ x b) & 8 & $5,6685^{\mathrm{ns}}$ & $0,2242^{* *}$ & $0,01423^{* *}$ \\
\hline Blocos & 4 & $64,9186^{* *}$ & $1,7978^{\mathrm{ns}}$ & $0,06891^{\mathrm{ns}}$ \\
\hline Resíduos & 56 & 19,9488 & 1,9225 & 0,24676 \\
\hline C.V\% & & 8,41 & 17,15 & 15,32 \\
\hline
\end{tabular}

** significativo ao nível de $1 \%$ de probabilidade $(p<0,01)$

* significativo ao nível de $5 \%$ de probabilidade $(0.01=<p<0.05)$.

${ }^{n s}$ não significativo ( $p>=.05$ ).

As médias de altura do relvado das espécies forrageiras e época de corte encontram-se na Tabela 2. Observa-se que apesar da mombaça irrigada apresentar maior altura em relação às demais forrageiras, a altura do relvado não foi influenciada pela época de corte.

A maior altura do relvado afeta negativamente o consumo pela menor participação de folhas nas camadas superiores do relvado com o avanço na idade, a qual apresenta alta correlação com o tamanho do bocado (PENNING et al., 1991), em função da dificuldade de apreensão da forragem com a presença de pseudocolmos mais longos.

A altura média das plantas na pastagem indica a quantidade de forragem em oferta (PENNING et al., 1991; ALMEIDA et al., 2000; FAGUNDES et al., 1999), pois pode determinar diferenças no desempenho animal e na quantidade de produto animal comercializável por unidade de área (MARASCHIN 1994).

Fica evidente a importância da irrigação para o acúmulo de fitomassa em pastagens, quando se observa as médias da altura do relvado. $\mathrm{O}$ acúmulo de forragem em pastagens é resultado da interação complexa entre os atributos genéticos de uma dada espécie, o efeito do ambiente sobre os seus processos fisiológicos e as características morfofisiológicas, para a determinação da produtividade (SILVA E PEDREIRA, 1997).

Conforme apontamentos de Aguiar (2000), a irrigação da pastagem de capim mombaça tem aumentado a altura total da planta, a taxa de crescimento, a taxa de acúmulo de forragem, determinando maior capacidade de suporte. Segundo Andrade et al (2002), a irrigação em pastagens tem sido relacionada com o aumento e a formação de tecidos na planta.

O tifton 85 irrigado apresentou altura de relvado (Tabela 2) média acima do encontrado por Aguiar et. al (2005), que observou altura média de $34,21 \mathrm{~cm}$ em condições de irrigação e $31,97 \mathrm{~cm}$ quando cultivada sob sequeiro. Em pesquisas realizadas sobre o parâmetro de crescimento do tifton-85, Aguiar et al (2006) observaram altura média de $38,75 \mathrm{~cm}$ para o tifton- 85 irrigado. 
De acordo com Teixeira et al (2013), pastagens de tifton 85 irrigadas possibilitam uma taxa de lotação média superior ao obtido em sistemas de sequeiro.

Tabela 2: Altura do Relvado $(\mathrm{cm})$ de espécies forrageiras cultivadas sob irrigação e sequeiro em três épocas de corte.

\begin{tabular}{lc}
\hline Fatores & Altura $(\mathrm{cm})$ \\
\hline Espécie & \\
Brachiaria irrigada & $51,20 \mathrm{~b}$ \\
Brachiaria não irrigada & $18,57 \mathrm{~d}$ \\
Mombaça irrigada & $108,76 \mathrm{a}$ \\
Mombaça não irrigada & $44,91 \mathrm{c}$ \\
Tifton 85 irrigado & $42,20 \mathrm{c}$ \\
\hline Época de Corte & \\
25 Dias & $52,56 \mathrm{a}$ \\
50 Dias & $53,30 \mathrm{a}$ \\
75 Dias & $53,51 \mathrm{a}$ \\
\hline As méch
\end{tabular}

As médias seguidas pela mesma letra não diferem estatisticamente entre si. Foi aplicado teste de Tukey ao nível de $5 \%$ de probabilidade.

As produções de massa fresca e massa seca estão apresentadas na Tabela 3. Observa-se que em todas as épocas de corte, como esperado, houve diferenças entre as espécies na produção de massa fresca, no entanto não foi observado uma ação significante entre as épocas de corte para esse fator.

A produção de massa fresca por mombaça irrigada se sobressaiu as demais espécies, mantendo alta produção para todas as épocas de corte, o que pode estar ligado principalmente pelo uso de adubação nitrogenada. A altura do pasto é consequência do tempo de rebrotação da gramínea e de suas adaptações morfológicas durante esse processo. Portanto, a altura do pasto pode comprometer o valor nutritivo da forragem em virtude do alongamento do colmo, aumentando os componentes estruturais da parede celular, principalmente da lignina, diminuindo o conteúdo celular e a taxa de bocados, comprometendo a ingestão diária de matéria seca (POMPEU et al., 2008).

A baixa produção de matéria fresca das espécies não irrigadas se deve a situação desfavorável das plantas ao ser submetidas à baixa precipitação pluvial, sendo que este seria o fator limitante para o desenvolvimento das plantas durante o período de experimento. Paciullo et al. (2003), encontraram resultados parecidos para redução da produção de massa fresca em situação de baixa precipitação pluvial associada a redução de temperatura e fotoperíodo.

Viana et al. (2007), obtiveram resultados que demonstraram que a produção de fitomassa foi significativamente afetada pelo estresse hídrico imposto às plantas no sistema de sequeiro. Em estresse hídrico há redução do ritmo de crescimento da planta e com isso acúmulo de solutos (nutrientes) nas células, o que melhora sua qualidade. Por outro lado, períodos prolongados de estresse hídrico podem promover o


microorganismos no rúmen (WILSON \& MERTENS, 1995).

Em relação à produção de massa seca a mombaça irrigada obteve uma maior produção seguida por mombaça não irrigada, diferindo das demais forrageiras sendo que a brachiaria não irrigada apresentou menor produção de massa seca. 
Não houve influência da época de corte na obtenção das médias de massa seca para nenhuma das espécies avaliadas. Não ocorreu interação de época de corte com a mombaça irrigada e não irrigada, que conseguiram manter seu índice de produção, independente da época de cortes.

Maldonado et al. (1997) avaliaram o efeito da irrigação, durante os períodos seco e chuvoso, sobre a produção de matéria seca do capim-elefante. Os autores verificaram que, para as condições das regiões Norte e Noroeste do Estado do Rio de Janeiro (temperatura de $22^{\circ} \mathrm{C}$ e 5,9 horas de insolação por dia), o capim-elefante apresenta uma resposta viável à irrigação, na produção de matéria seca, eliminando a estacionalidade de produção.

Segundo apontamentos de Costa et al (2004), a idade de corte afeta o rendimento da forragem colhida, resultando em incrementos significativos na produção de matéria seca à medida que se aumenta a idade de corte (COSTA et al., 2004). Assim, Santana et al., (1989), trabalhando com três cultivares de capimelefante (Cameroon, Mineiro e Napier de Goiás), submetidas a três intervalos de cortes (28, 56 e 84 dias), verificaram incrementos na produção de matéria seca quando o intervalo de corte aumentou de 28 para 84 dias.

Farias et al. (2007) afirmaram que a evolução da massa seca de forragem total (MSFT, kg MS/ha) e da massa seca de forragem verde (MSFV, kg MS/ha), em relação à idade de rebrotação e a interceptação da radiação fotossinteticamente ativa (IRFA), fez com que ocorresse a elevação ao longo do período de descanso (PD), para a MSFV E MSFT. Até o ponto de IRFA de $95 \%$, sendo a sua referida idade de 28 dias, as duas massas apresentavam-se semelhantes, onde a partir desse ponto a MSFT passou a ser maior que a MSFV o implica dizer que a partir desse ponto, uma fração de forragem produzida iniciava seu processo de senescência.

Diferentemente dos resultados encontrados nessa pesquisa, Azevedo Junior (2011) observou a existência de interação entre irrigação e frequências de corte para a massa seca total, onde pastos de capim piatã irrigados cortados aos 21 dias apresentaram a menor massa seca total, o que decorreu provavelmente da lâmina de água utilizada.

Nesse sentido, Maranhão (2008), trabalhando com B. decumbens em Itapetinga Bahia, concluiu que para aumento na produção de matéria seca, os intervalos entre cortes variáveis de 39 dias no verão e 21 dias no outono e inverno mostram-se mais favoráveis para a produção diária de forragem, quando comparado aos respectivos intervalos fixos.

Diferentemente da brachiaria e da mombaça cultivadas sob irrigação, o tifton 85 irrigado apresentou um decréscimo de crescimento para a terceira época de corte. O mau desempenho do tifton 85 para essa característica acaba afetando a produção de fitomassa, e pode ser explicado pela inadaptabilidade do mesmo para a região, principalmente devido à temperatura, uma vez que pode ser observado que em locais sombreados esse material apresentou melhores características morfológicas. A falta de adaptação ao local fez com que ocorresse uma dificuldade no processo de rebrotação do mesmo.

Apesar do tifton 85 representar uma boa opção para alimentação de ruminantes, em decorrência de sua boa qualidade e de seu potencial de produção de biomassa (VILELA e ALVIM, 1998), este não obteve um bom desempenho na produção de fitomassa. 
Cecato et al. (1994), trabalhando com $P$. maximum cv. Aruana, observaram que o aumento do intervalo de cortes de 28 para 35 dias acarretou em maior produção de matéria seca, sendo que não houve diferença entre cortes aos 35, 42 e 49 dias.

Tabela 3: Produção de Fitomassa (t/ha) de espécies forrageiras sob irrigação e sequeiro em três épocas de corte.

\begin{tabular}{lccc}
\hline & \multicolumn{3}{c}{ Épocas de Corte } \\
\cline { 2 - 3 } Espécie & $25 \mathrm{Dias}$ & 50 Dias & 75 Dias \\
\hline & & & \\
Brachiaria irrigada & & MASSA FRESCA & $5,33 \mathrm{bA}$ \\
Brachiaria não irrigada & $4,94 \mathrm{bA}$ & $5,31 \mathrm{bA}$ & $2,06 \mathrm{cA}$ \\
Mombaça irrigada & $2,06 \mathrm{cA}$ & $2,00 \mathrm{cA}$ & $19,10 \mathrm{aA}$ \\
Mombaça não irrigada & $18,78 \mathrm{aA}$ & $18,80 \mathrm{aA}$ & $6,87 \mathrm{bA}$ \\
Tifton irrigado & $6,89 \mathrm{bA}$ & $6,84 \mathrm{bA}$ & $7,71 \mathrm{bA}$ \\
& $6,88 \mathrm{bA}$ & $7,68 \mathrm{bA}$ & \\
Brachiaria irrigada & & MASSA SECA & $1,76 \mathrm{cdA}$ \\
Brachiaria não irrigada & & $1,76 \mathrm{cdA}$ & $0,97 \mathrm{dA}$ \\
Mombaça irrigada & $1,90 \mathrm{cA}$ & $0,96 \mathrm{dA}$ & $7,16 \mathrm{aA}$ \\
Mombaça não irrigada & $0,99 \mathrm{dA}$ & $7,06 \mathrm{aA}$ & $4,60 \mathrm{bA}$ \\
Tifton irrigado & $7,06 \mathrm{aA}$ & $4,60 \mathrm{bA}$ & $1,99 \mathrm{cA}$ \\
\hline
\end{tabular}

Médias acompanhadas de letras maiúsculas diferentes nas colunas e minúsculas nas linhas diferem entre si $(P<0,05)$ pelo teste $F$.

\section{CONCLUSÕES}

A produção do capim mombaça (Panicum maximum cv. Mombaça) quando cultivado com irrigação apresentou maior altura e produção fitomassa quando comparado com as demais forrageiras avaliadas.

Após as investigações ficou evidente que a altura do relvado e produção de fitomassa não foram influenciadas pela época de corte.

\section{REFERÊNCIAS}

AGUIAR, A. P. A.. Uso de forrageiras do grupo Panicum em pastejo rotacionado para vacas leiteiras. In: SIMPÓSIO DE FORRAGICULTURA E PASTAGENS: TEMAS EM EVIDÊNCIAS. Anais. Lavras: Universidade Federal de Lavras, 2000. p.69146.

AGUIAR, A. P. A.; DRUMOND, L. C. D.; FELIPINI, T. M.; PONTES, P. O.; SILVA, A. M.. Características de crescimento de pastagens irrigadas e não irrigadas em ambiente de cerrado. FAZU em Revista, Uberaba, n.2, p.22-26, 2005.

AGUIAR, A. P. A.; DRUMOND, L. C. D.; CAMARGO, A.; MINMA, J. H.; SCANDIUZZI, R. N.; RESENDE, J. R.; APONTE, J. E. E. Parâmetros de crescimento de uma pastagem de tifton 85 (. cynodon dactylon. $x$.cynodon nlemfuensis. cv. tifton 68) irrigada e submetida ao manejo intensivo do pastejo. FAZU em Revista, Uberaba, n.3, p.25-27, 2006.

ALMEIDA, E. X.; MARASCHIN, G. E.; HARTHMANN, O. E. L.; RIBEIRO FILHO, H. M. N.; SETELICH, E. A.. Oferta de forragem de capim-Elefante Anão Mott e a dinâmica da pastagem. Revista Brasileira de Zootecnia, v.29, p.12811287, 2000.

ÁLVARES, J. A. S.; HOLANDA JÚNIOR, E. V.; MELO, M. V. M; MADALENA, F. E.. Produção de Leite em Pastagens Irrigadas. In: ENCONTRO DE PRODUTORES DE F1, 3. Anais. Belo Horizonte: 2000. p.23-32.
ANDRADE, A. C.; FONSECA, D. M.; LOPES, R. S.. Disponibilidade de massa seca e composição química do capim-Elefante Napier sob adubação e irrigação. In: REUNIÃO ANUAL DA SOCIEDADE BRASILEIRA DE ZOOTECNIA, 41. Anais. Campo Grande: Sociedade Brasileira de Zootecnia, 2004.

AZEVEDO JUNIOR, N. P.. Produção e composição bromatológica do capim-Piatã em diferentes frequências de corte sob irrigação. Dissertação (Mestrado em Zootecnia) - Universidade Federal da Grande Dourados, Dourados, 2011.

CECATO, U.. Influência da freqüência de corte, níveis e formas de aplicação do nitrogênio sobre a produção, composição química e algumas características da rebrota do capimAruana (Panicum maximum Jacq. cv. Aruana). Jaboticabal: Universidade Estadual Paulista. Tese (Doutorado em Produção Animal) - Universidade Estadual Paulista, 1993.

COSTA, N. L.; TOWNSEND, C. R.; MAGALHÃES, J. A.; PEREIRA, R. G. A.. Curva de crescimento e composição química de Paspalum atratum Bra-009610 em Rondônia. In: ZOOTEC, 2004. Anais. Brasília: ABZ/AZOO, 2004.

CUNHA, F. F.; SOARES, A. A.; PEREIRA, O. G.; LAMBERTUCCI, D. M.; ABREU, F. V. S.. Características morfogênicas e perfilhamento do Panicum maximum Jacq. cv. Tanzânia 
irrigado. Ciência e Agrotecnologia, Lavras, v.31, n.3, p.628635, 2007.

DETOMINI, E. R.. Modelagem da produtividade potencial de Brachiaria brizantha (variedades cultivadas Marandu e Xaraés). Dissertação (Mestrado) - Escola Superior de Agricultura Luiz de Queiroz, Piracicaba, 2004.

DRUMOND, L. C. D.. Aplicação de água residuária de suinocultura por aspersão em malha: desempenho hidráulico e produção de matéria seca de Tifton 85 . Tese (Doutorado em Agronomia) - Universidade Estadual Paulista, Jaboticabal, 2003.

DRUMOND, L. C. D.; AGUIAR, A. P. A.. Irrigação de pastagem. Uberaba: FAZU, 2005.

EMBRAPA. Sistema brasileiro de classificação de solos. 3 ed. Brasília, 2013.

FAGUNDES, J. L.; SILVA, S. C.; PEDREIRA, C. G. S.. CARNEVALLI R. A.; CARVALHO, C. A. B.; SBRISSIA, A. F.; PINTO, L. F. M.. Intensidades de pastejo e a composição morfológica de pastos de Cynodon spp. Scientia Agrícola, v.56, n.4, 1999.

FARIAS, S. F.; CUTRIM JUNIOR, J. A A.; BEZERRA, A. P. A.; CÂNDIDO, M. J. D.; AQUINO, R. M. S.; SOMBRA, W. A.; ANDRADE, R. R.. Componentes da biomassa inicial do dossel de tifton-85. In: SIMPÓSIO INTERNACIONAL SOBRE CAPRINOS E OVINOS DE CORTE, 3. Anais. João Pessoa, 2007.

FERREIRA, D. J.; ZANINE, A. M.. Importância da pastagem cultivada na produção da pecuária de corte brasileira. Revista Eletrônica de Veterinária, v.8, n.3, 2007, p.1-18.

GONÇALVES, G. D.; SANTOS, G. T.; CECATO, JOBIM, C. C.; DAMASCENO, J. C., BRANCO, A. F.; FARIA, K. P.. Produção e valor nutritivo de gramíneas do gênero Cynodon em diferentes idades ao corte durante o ano. Acta Scientiarum, v.24, n.4, p.1163-1174, 2002.

LIMA, G. F. C.; AGUIAR, E. M.; MACIEL, F. C.. Secador solar: a fábrica de feno para a agricultura familiar. In:

Armazenamento de forragens para agricultura familiar. Natal: Empresa de Pesquisa Agropecuária do Rio Grande do Norte, 2004.

LIMA, D. O. S.. Características agronômicas do capim-piatã submetido a doses de nitrogênio e alturas de corte. Dissertação (Mestrado em Agricultura Tropical) Universidade Federal de Mato Grosso, Faculdade de Agronomia e Medicina Veterinária, 2009.

MALDONADO, H.; DAHER, R. F.; PEREIRA, A. V.; FERNANDES, A. M.; SOARES, C. S.; SILVA, L. C. C.; BORGES, A.. Efeito da irrigação na produção de matéria seca do capim-elefante (Pennisetum purpureum Schum) em Campos dos Goytacazes, RJ. In: REUNIÃO ANUAL DA SOCIEDADE BRASILEIRA DE ZOOTECNIA, 34. Anais. Juiz de Fora: SBZ, 1997.

MARANHÂO, C. M. A.. Características Produtivas, Morfogênicas e Estruturais do Capim-Braquiária Submetido a Intervalos de Cortes e Adubação Nitrogenada. Dissertação (Mestrado em Zootecnia) - Universidade Estadual do Sudoeste da Bahia, Itapetinga, 2008.
MARASCHIN, G. E.. Avaliação de forrageiras e rendimento de pastagens com o animal em pastejo. In: SIMPÓSIO INTERNACIONAL DE FORRAGICULTURA. REUNIÃO ANUAL DA SOCIEDADE BRASILEIRA DE ZOOTECNIA, 31. Anais. Maringá: Universidade Estadual de Maringá, 1994.

MARTINS, A. M.; FERREIRA, D.; MOURA, E.; SCHERER, F.; TIRLONI, M. A.; BEHLING O.; PINTO P.; INFANTINO, M.; PASQUALLI, S.. Levantamento sobre a morte de pastagem em Mato Grosso. Cuiabá: IMEA, 2011.

PACIULLO, D. S. C.; MATTOS, J. L. S.; GOMIDE, J. A.; QUEIROZ, D. S.; SILVA, E. A. M.. Proporção de tecidos espessura da parede celular em espécies de braquiária, cultivadas sob diferentes níveis de umidade do solo. In: REUNIÃO ANUAL DA SOCIEDADE BRASILEIRA DE ZOOTECNIA, 36. Anais. São Paulo: Sociedade Brasileira de Zootecnia, 1999.

PEDREIRA, C. G. S.. Avanços metodológicos na avaliação de pastagens. In: SIMPÓSIO DE FORRAGICULTURA NA REUNIÃO ANUAL DA SOCIEDADE BRASILEIRA DE ZOOTECNIA, 39. Anais. Recife: SBZ, 2002.

PENNING, P. D., PARSONS, A. J., ORR, R. J.; TREACHER, T. T.. Intake and behaviour responses by sheep to changes in sward characteristics under continuous stocking. Grass and Forage Science, v.46, p.15-28, 1991.

POMPEU, R. C. F. F.; CÂNDIDO, M. J. D.; NEIVA, J. N. M.; ROGÉRIO, M. C. P.; FACÓ, O.. Componentes da biomassa pré-pastejo e pós-pastejo de capim-tanzânia sob lotação rotativa com quatro níveis de suplementação concentrada. Revista Brasileira de Zootecnia, Viçosa, v.37, n.3, p.383-393, 2008.

RADIS, A. C.. Características estruturais e valor nutritivo de B. brizantha. cv. Piatã em diferentes idades e altura de corte. Dissertação (Mestrado em Zootecnia) - Universidade Estadual do Oeste do Paraná, 2010.

RESTLE, J.; ROSO, C.; SOARES, A. B.. Produtividade animal e retorno econômico em pastagem de aveia preta mais azevém adubada com fontes de nitrogênio em cobertura. Revista Brasileira de Zootecnia, v.29, n.2, p.357$364,2000$.

ROLIM, F. A. Estacionalidade de produção de forragens. In: SIMPÓSIO SOBRE MANEJO DE PASTAGENS, 6. Anais. São Paulo: USP, 1980.

SANTANA, J. R.; PEREIRA, J. M.; ARRUDA, N. G.. Avaliação de cultivares de capim-elefante (Pennisetum purpureum, Schum.) no sul da Bahia. Revista Sociedade Brasileira de Zootecnia, v.3, n.18, p.273-283, 1989.

SCALEA, M. J.. Programa Renovação de Pastagens no Cerrado. Goiânia: Monsanto, 1997.

SEPLAN. Secretaria de Planejamento do Estado de Mato Grosso. Mato Grosso: Solos e Paisagens. Cuiabá, 2007.

SILVA, S. C.; PEDREIRA, C. G. S.. Princípio da Ecologia Aplicado ao Manejo de Pastagem. In: SIMPÓSIO DE ECOSSISTEMA DE PASTAGENS, 3. Anais. Jabuticabal: FUNEP, 1997. 
SOUSA, D. M. G.; LOBATO, E.. Cerrado: correção de solo e adubação. Brasília: Embrapa Informações Tecnológica, 2004.

TEODORO, R. E. F.. Pastejo irrigado e pivô central. In: SIMPÓSIO GOIANO SOBRE MANEJO E NUTRIÇÃO DE BOVINOS DE CORTE, 4. Anais. Goiânia: Colégio Brasileiro de Nutrição Animal, 2002.

VIANA, M C. M.; QUEIROZ, C. G. S.; LEMOS, F. J. P.. Acúmulo de fitomassa e índice de área foliar de gramíneas forrageiras em sistema irrigado e de sequeiro. In: REUNIÃO ANUAL DA SOCIEDADE BRASILEIRA DE ZOOTECNIA, 44. Anais.

Jabuticabal: Unesp, 2007.
VILELA, H.. Pastagem: seleção de plantas forrageiras, implantação e adubação. Viçosa: Aprenda Fácil, 2005.

VILELA, D.; ALVIM, M. J.. Manejo de pastagens do gênero Cynodon: Introdução, caracterização e evolução do uso no Brasil. In: SIMPÓSIO SOBRE MANEJO DA PASTAGEM, 15. Anais. Piracicaba: FEALQ, 1998.

WILSON, J. R.; MERTENS, D. R.. Cell wall accessibility and cell structure limitations to microbial digestion of forage. Crop Science, v.35, n.1, p.251-259, 1995.

YASSU, F.; PITOMBO, L. H.; FRANCO, M. Reportagem de capa: Irrigação. Revista DBO Rural, São Paulo, n.218, p.5064, 1998. 